\title{
Need for evidence on long-term prognosis of PD+HD: a commentary
}

\author{
Mototsugu Tanaka ${ }^{1 *}$ (D) and Naobumi Mise ${ }^{2}$
}

\begin{abstract}
Combination therapy with peritoneal dialysis and hemodialysis (PD+HD) is an alternative dialysis method for patients with end-stage kidney disease (ESKD). The complementary use of once-weekly HD expedites to achieve adequate dialysis and enables to prolong PD duration. Although PD+HD has been widely employed among Japanese PD patients, it is much less common outside Japan. Clinical evidences are still not enough, especially in long-term prognosis and appropriate treatment duration, suitable patients, and generalizability. A retrospective cohort study by Chung et al. (BMC Nephrol 21:348, 2020) compared the risk of mortality and hospitalization between PD patients who were transferred to PD+HD and those who were transferred to HD in Taiwan. Because the mortality and hospitalization rates did not differ between the groups, the authors concluded that, PD+HD may be a rational and cost-effective treatment option. It should be noted that the effects of PD+HD on long-term prognosis are still unknown due to too-short PD+HD duration. However, the study identified the high-risk patient population and showed the generalizability of PD+HD. PD+HD is a treatment of choice in patients with ESKD who prefer PD lifestyles even after decline in residual kidney function.
\end{abstract}

Keywords: Peritoneal dialysis, Hemodialysis, Combined dialysis, End-stage kidney disease, End-stage renal disease, Residual kidney function, Technique failure, Precision medicine

\section{Background}

Combination therapy with peritoneal dialysis and hemodialysis (PD+HD) has been widely used in Japan (Fig. 1). Currently, one-fifth of Japanese PD patients are on $\mathrm{PD}+\mathrm{HD}$, and $87.9 \%$ of those are treated with 5 to 6 days of PD and once-weekly HD (Japanese Society for Dialysis Therapy, unpublished data), which is covered by the national health insurance as a maintenance dialysis. Since the complementary use of HD ameliorates underdialysis and overhydration and enables significant prolongation of $\mathrm{PD}, \mathrm{PD}+\mathrm{HD}$ is preferred by $\mathrm{PD}$ patients who wish to maintain PD lifestyles after decline in residual kidney function $[1,2]$. In fact, health-related quality of life for $\mathrm{PD}+\mathrm{HD}$ was close to that for PD but was

\footnotetext{
* Correspondence: motanaka-tky@umin.ac.jp

${ }^{1}$ Division of Nephrology and Endocrinology, The University of Tokyo School of Medicine, 7-3-1 Hongo, Bunkyo-ku, Tokyo 113-8655, Japan

Full list of author information is available at the end of the article
}

better than HD in role and social functions [3]. In this cohort, hospitalization risk was similar between PD+HD and HD, although $\mathrm{PD}+\mathrm{HD}$ may have a higher hospitalization risk of dialysis access-related complications than HD [4]. However, many of these findings were from low quality studies, and several important arguments, such as long-term prognosis and appropriate treatment duration, and suitable patients, have not been determined. The generalizability of $\mathrm{PD}+\mathrm{HD}$ was also unclear, since there have been few reports from outside Japan so far.

\section{PD+HD compared to HD}

Chung et al. recently reported a retrospective cohort study comparing the risk of mortality and hospitalization (including emergent hospital visits) between $\mathrm{PD}+\mathrm{HD}$ group (transfer from $\mathrm{PD}$ to $\mathrm{PD}+\mathrm{HD}$ ) and $\mathrm{HD}$ group (transfer from $\mathrm{PD}$ to $\mathrm{HD}$ ) using a health insurance

C C The Author(s). 2021 Open Access This article is licensed under a Creative Commons Attribution 4.0 International License, which permits use, sharing, adaptation, distribution and reproduction in any medium or format, as long as you give appropriate credit to the original author(s) and the source, provide a link to the Creative Commons licence, and indicate if changes were made. The images or other third party material in this article are included in the article's Creative Commons licence, unless indicated otherwise in a credit line to the material. If material is not included in the article's Creative Commons licence and your intended use is not permitted by statutory regulation or exceeds the permitted use, you will need to obtain permission directly from the copyright holder. To view a copy of this licence, visit http://creativecommons.org/licenses/by/4.0/ The Creative Commons Public Domain Dedication waiver (http://creativecommons.org/publicdomain/zero/1.0/) applies to the data made available in this article, unless otherwise stated in a credit line to the data. 


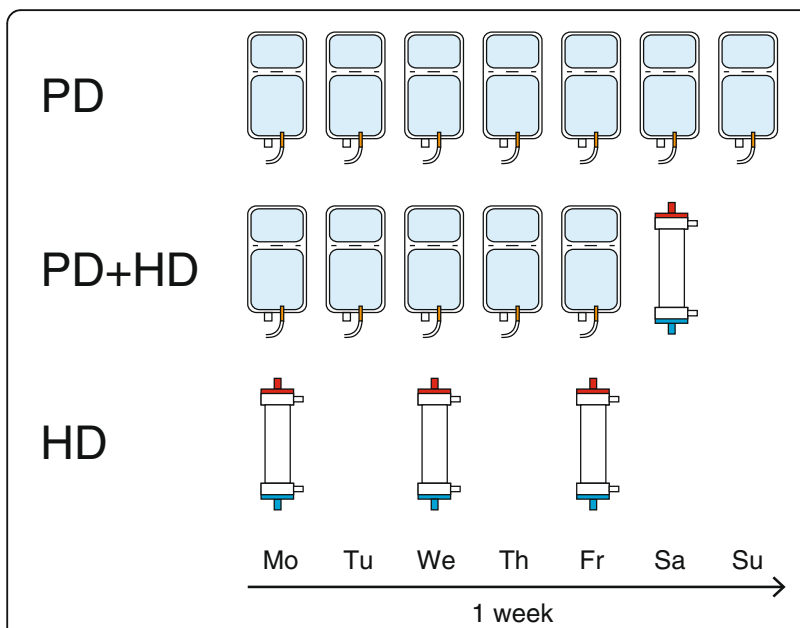

Fig. 1 Treatment patterns of each dialysis modality. Shown are examples of treatment schedule in a week among PD, PD+HD, and HD. For each modality, the frequency of treatment can be modified based on patient characteristics. PD+HD may be used as either a bridging therapy or a maintenance therapy. Complementary use of $\mathrm{HD}$ increases dialysis doses and fluid removal in PD patients after decline in residual kidney function. PD+HD may also allow "PDholiday" that mitigates excessive exposure to glucose dialysate. Abbreviations: HD, hemodialysis; PD, peritoneal dialysis; PD+HD, combination therapy with peritoneal dialysis and hemodialysis

database in Taiwan [5]. An intention-to-treat analysis revealed that both risks were similar between the two groups, although peritonitis was a strong risk factor for hospitalization in $\mathrm{PD}+\mathrm{HD}$. The authors concluded that $\mathrm{PD}+\mathrm{HD}$ is a safe, rational, and may be a cost-effective treatment for patients with end-stage kidney disease (ESKD), and the larger number of patients and longer observation period than previous studies may strengthen the present study conclusion.

However, long-term prognostic effects of $\mathrm{PD}+\mathrm{HD}$ have not been clarified yet. In the present study, about $58 \%$ of patients were transferred from $\mathrm{PD}+\mathrm{HD}$ to $\mathrm{HD}$ within a year. Too-short $\mathrm{PD}+\mathrm{HD}$ duration makes it difficult to understand the crude effects of the combined dialysis in a 12-year follow-up. In addition, it remains unclear whether patients with ESKD can be treated adequately with $\mathrm{PD}+\mathrm{HD}$ for a long period. A multivariate analysis including $\mathrm{PD}+\mathrm{HD}$ duration may help to understand the long-term prognostic impacts and appropriate treatment period of this combined modality.

Nevertheless, the present study provided an important finding that $\mathrm{PD}+\mathrm{HD}$ had a similar prognosis to $\mathrm{HD}$, which was compatible with a recent Japanese study [4]. The consistency of the results from different regions suggested the feasibility and generalizability of PD+HD. There may be some differences in health insurance policies and the treatment strategies for additional HD between Japan and Taiwan. While once-weekly HD is routinely performed in most Japanese $\mathrm{PD}+\mathrm{HD}$ patients, the study showed that a half of $\mathrm{PD}+\mathrm{HD}$ patients in Taiwan were treated with only two HD sessions per month, and in such patients, HD was sometimes used as a rescue treatment. This biweekly HD regimen of PD+ HD may increase the generalizability in developing countries.

The present study also suggested that $\mathrm{PD}+\mathrm{HD}$ can be prescribed as an individualized, bridging dialysis modality. The flexibility may enable a smooth and appropriate transition of dialysis modality, and it may be of help during disastrous situations, such as recent COVID-19 pandemic [6]. On the other hand, dialysis access-related complications [4] and peritonitis [5] were risk factors of hospitalization for $\mathrm{PD}+\mathrm{HD}$, and technique survival rate was poor in those who required high ultrafiltration volume by additional HD [7]. It is necessary to identify suitable patients and establish the optimal indication for $\mathrm{PD}+\mathrm{HD}$.

In the present study, the authors proposed $\mathrm{PD}+\mathrm{HD}$ as a part of an integrated dialysis care and mentioned that dialysis staff should be familiar with this combined modality. A patient-centered dialysis prescription by the shared decision-making is desired [8], however, many patients are feeling that they had not been sufficiently explained about dialysis modalities at the start of dialysis [9]. An increased awareness of PD+HD would provide patients more treatment choices in the precision medicine era.

\section{Conclusions}

A recent study by Chung et al. suggested that mortality and hospitalization risks were similar between PD patients who were transferred to $\mathrm{PD}+\mathrm{HD}$ and those who were transferred to HD in Taiwan [5]. However, the effects of $\mathrm{PD}+\mathrm{HD}$ on long-term prognosis was unclear, since the treatment duration of $\mathrm{PD}+\mathrm{HD}$ was too-short in the study. Nevertheless, this interesting paper provided several important findings. Firstly, PD+HD may be a safe, feasible, and flexible dialysis modality which is generalizable both in Japan and Taiwan. Secondary, patients with recent peritonitis were at a high risk of hospitalization. Clinicians and nurses should have a good understanding of $\mathrm{PD}+\mathrm{HD}$ to apply precision medicine in clinical practice.

\section{Abbreviations \\ PD+HD: Combination therapy with peritoneal dialysis and hemodialysis; ESKD: End-stage kidney disease; COVID-19: Coronavirus disease 2019}

\section{Acknowledgements}

Not applicable.

\section{Authors' contributions}

MT conceived and wrote the first draft of the manuscript. NM supervised the manuscript. Both authors read and approved the final manuscript. 


\section{Funding}

Not applicable.

\section{Availability of data and materials Not applicable.}

Ethics approval and consent to participate

Not applicable

\section{Consent for publication}

Not applicable

\section{Competing interests}

Not applicable

\section{Author details}

'Division of Nephrology and Endocrinology, The University of Tokyo School of Medicine, 7-3-1 Hongo, Bunkyo-ku, Tokyo 113-8655, Japan. ${ }^{2}$ Department of Nephrology, Division of Internal Medicine, Mitsui Memorial Hospital, 1 Kanda-izumi-cho, Chiyoda-ku, Tokyo 101-8643, Japan.

Received: 9 November 2020 Accepted: 14 December 2020

Published online: 07 January 2021

\section{References}

1. Kawanishi H, Hashimoto Y, Nakamoto H, Nakayama M, Tranaeus A. Combination therapy with peritoneal dialysis and hemodialysis. Perit Dial Int. 2006;26(2):150-4.

2. Kawanishi H, Moriishi M. Clinical effects of combined therapy with peritoneal dialysis and hemodialysis. Perit Dial Int. 2007;27(Suppl 2):126-9.

3. Tanaka M, Ishibashi Y, Hamasaki Y, Kamijo Y, Idei M, Kawahara T, Nishi T, Takeda M, Nonaka H, Nangaku M, et al. Health-related quality of life on combination therapy with peritoneal dialysis and hemodialysis in comparison with hemodialysis and peritoneal dialysis: a cross-sectional study. Perit Dial Int. 2020;40(5):462-9. https://doi.org/10.1177/ 0896860819894066.

4. Tanaka M, Ishibashi Y, Hamasaki Y, Kamijo Y, Idei M, Kawahara T, Nishi T, Takeda M, Nonaka H, Nangaku M, et al. Hospitalization for Patients on Combination Therapy With Peritoneal Dialysis and Hemodialysis Compared With Hemodialysis. Kidney Int Rep. 2020;5(4):468-74.

5. Chung MC, Yu TM, Wu MJ, Chuang YW, Muo CH, Chen CH, Chang CH Shieh JJ, Hung PH, Chen JW, et al. Is combined peritoneal dialysis and hemodialysis redundant? A nationwide study from Taiwan. BMC Nephrol. 2020;21(1):348

6. Matsuo N, Yokoyama K, Tanno Y, Yamamoto I, Yokoo T. Combined therapy using peritoneal dialysis and hemodialysis may increase the indications for peritoneal dialysis in the United States. Kidney Int. 2015;87(6):1259-60.

7. Tanaka M, Ishibashi Y, Hamasaki Y, Kamijo Y, Idei M, Nishi T, Takeda M, Nonaka H, Nangaku M, Mise N. Ultrafiltration volume by once-weekly hemodialysis is a predictor of technique survival of combination therapy with peritoneal dialysis and hemodialysis. Ther Apher Dial. 2020. https://doi. org/10.1111/1744-9987.13509.

8. Blake PG, Brown EA. Person-centered peritoneal dialysis prescription and the role of shared decision-making. Perit Dial Int. 2020;40(3):302-9.

9. Dahlerus C, Quinn M, Messersmith E, Lachance L, Subramanian L, Perry E, Cole J, Zhao J, Lee C, McCall M, et al. Patient Perspectives on the Choice of Dialysis Modality: Results From the Empowering Patients on Choices for Renal Replacement Therapy (EPOCH-RRT) Study. Am J Kidney Dis. 2016; 68(6):901-10.

\section{Publisher's Note}

Springer Nature remains neutral with regard to jurisdictional claims in published maps and institutional affiliations.

Ready to submit your research? Choose BMC and benefit from:

- fast, convenient online submission

- thorough peer review by experienced researchers in your field

- rapid publication on acceptance

- support for research data, including large and complex data types

- gold Open Access which fosters wider collaboration and increased citations

- maximum visibility for your research: over $100 \mathrm{M}$ website views per year

At BMC, research is always in progress.

Learn more biomedcentral.com/submissions 